\title{
Transient thermographic evaluation of plastered mosaics
}

\author{
by M. Koui ${ }^{*}$, N.P. Avdelidis ${ }^{* *}$ and Ch. Arvanitis* \\ * Materials Science \& Engineering Section, School of Chemical Engineering, National Technical \\ University of Athens, Athens 15780, Greece. \\ ** IRT \& Materials Consultancy, Agia Triada Ano Volos, Volos 38500, Greece
}

\begin{abstract}
Since there are strict conservation regulations as far as mosaics and/or historical sites are concerned, the use of non-destructive testing and evaluation techniques is considered to be essential. Transient thermography in civil engineering can be used efficiently in a variety of applications. The mosaic beneath the plastered surface due to the different thermal diffusivity that it presents can be realised by different surface temperature. The thermal contrast curves between plain plastered surfaces and plastered mosaics were recorded. Special considerations concerning the applicability and accuracy of the used approach for this specific application are also presented.
\end{abstract}

\section{Introduction}

In view of the fact that destructive sectioning in the conservation interventions of mosaics is limited, the application of non-destructive techniques is considered to be essential. There have been various works where the employment of non destructive testing and evaluation techniques such as infrared thermography, proved to provide substantial information attainment concerning the investigation of materials and structures. Such examples include: moisture assessment in buildings and monuments [1], diagnosis of surface and near surface defects [2], as well as subsurface defects [3], evaluation of asphalt pavements [4], subsurface investigation of materials [5], materials characterisation [6].

Following an earlier work by two of the authors and others [7], in this work, different plastered mosaic surfaces, were investigated in the laboratory using transient thermography, in order to identify their sub surfaces - reveal of mosaics.

\section{Experimental techniques}

Different panels were prepared and tested in the laboratory, using transient thermography (Table 1). The mortar used for the preparation of the blank samples (materials and proportions) was the subsurface of all panels. The aggregate size distribution of all mortars was in the range of $0-1 \mathrm{~mm}$. Furthermore, in figure 1 , the cross section of an investigated panel is presented.

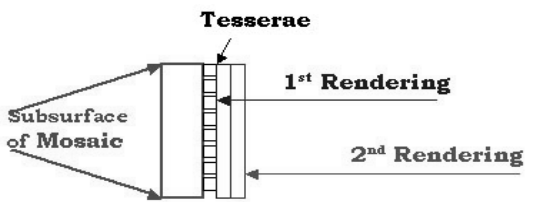

Fig. 1. Example of $X$ - Section of investigated panel 
Table 1. Description of samples

\begin{tabular}{|c|l|}
\hline Sample & \multicolumn{1}{|c|}{ Description } \\
\hline Blank 1 & Plastered mosaic surface with 2cm lime mortar \\
\hline Blank 2 & Plastered mosaic surface with 2cm hydraulic lime mortar \\
\hline S1 & $\begin{array}{l}\text { Mosaic with Gold and Enamel with 1cm coating of Hydraulic } \\
\text { Lime Mortar (HL/S:1/2.3) and a second 1cm coating of Lime } \\
\text { Mortar (L/S:1/1) }\end{array}$ \\
\hline S2 & $\begin{array}{l}\text { Marble Mosaic with 1cm coating of Hydraulic Lime Mortar } \\
(\mathrm{HL} / \mathrm{S}: 1 / 2.3) \text { and a second 1cm coating of Lime Mortar } \\
(\mathrm{L} / \mathrm{S}: 1 / 1)\end{array}$ \\
\hline S3 & $\begin{array}{l}\text { Mosaic with Gold and Enamel with 1cm coating of Hydraulic } \\
\text { Lime Mortar (HL/S:1/2.3) }\end{array}$ \\
\hline S4 & $\begin{array}{l}\text { Marble Mosaic with 1cm coating of Hydraulic Lime Mortar } \\
(\mathrm{HL} / \mathrm{S}: 1 / 2.3)\end{array}$ \\
\hline
\end{tabular}

Transient thermography, which is a well tested thermal non-destructive testing and evaluation procedure, was used, employing an Avio TVS 2300 Mk II ST (3 - 5.4 $\mu \mathrm{m})$ system and a Sony video-walkman connected to the processor for continuous recording of the thermal images. An external 1500 Watt heat source (quartz tube heater) was used in order to uniformly heat the inspected specimens (at a distance of $40 \mathrm{~cm}$ ).

The thermal excitation process was performed for approximately 1 hour for each sample, whilst the transient phase (recording during the cooling down procedure) was, depending on the sample, for more than one hour and up to 95 minutes. The relative temperature - time plots, as well as representative thermal images from the investigated panels are presented in the results section.

The dimensions of each investigated panel were $22 \mathrm{~cm}(\mathrm{~W}) \times 32 \mathrm{~cm}(\mathrm{H})$.

The experimental set-up is presented in figure 2, whereas in figure 3 the examined pairs - panels showing the temperature spots recorded are presented.

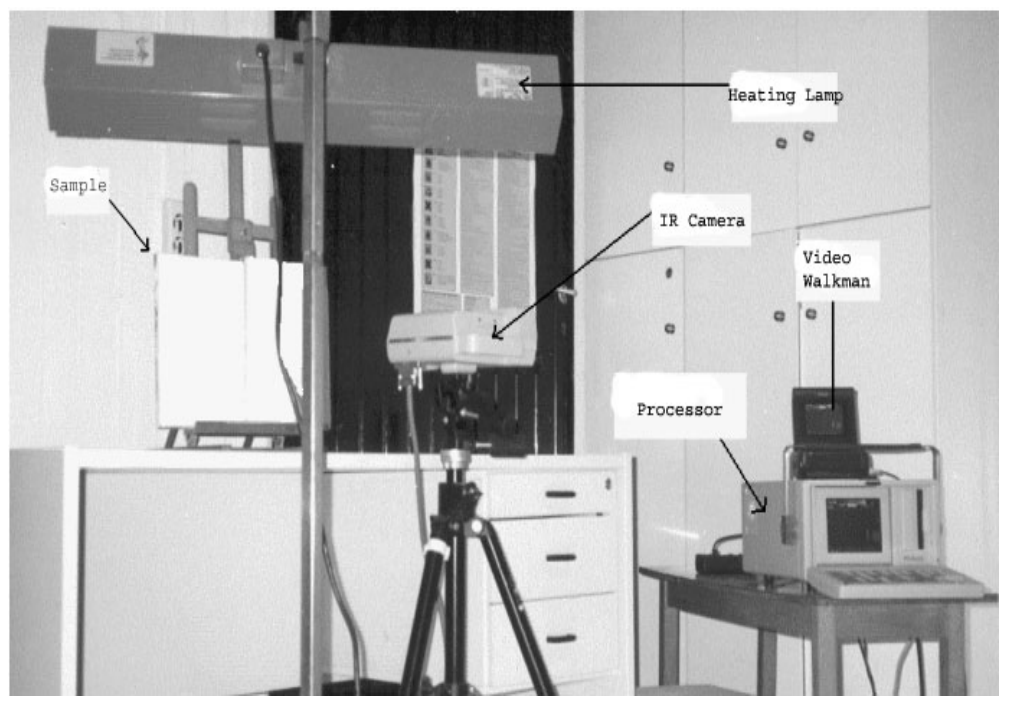

Fig. 2. Experimental set-up. 


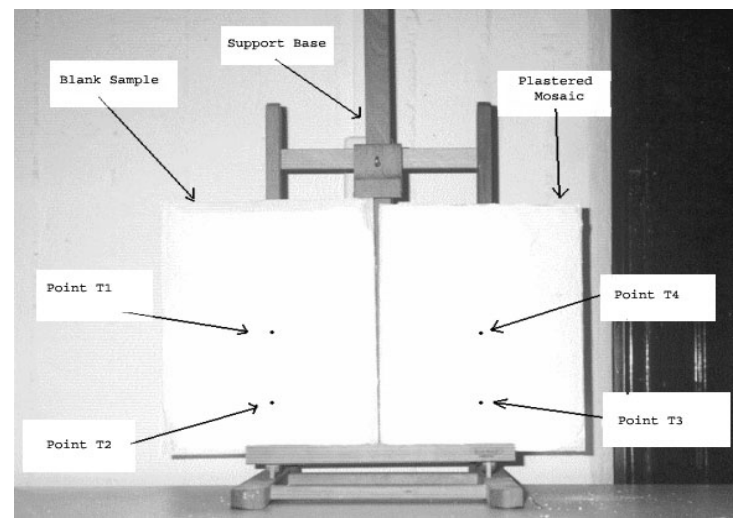

Fig. 3. Support base and panels under investigation.

\section{Results}

Due to the different thermal diffusion that each layer renders, transient thermography can detect the different sub surfaces on the plastered mosaics, presented with temperature variations on the surface.

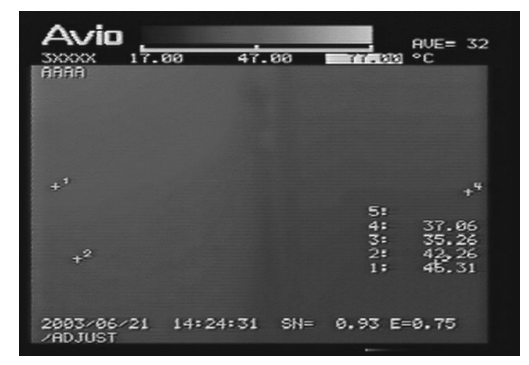

Fig. 4.Thermal image showing sample S1 (left) and the blank sample 1 (right) obtained at 22 minutes.

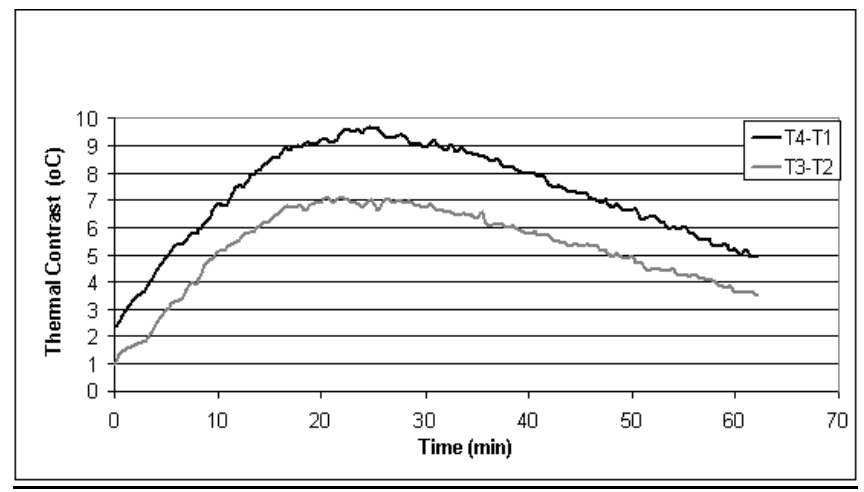

Fig. 5. Thermal contrast curves of blank sample 1 and sample S1. 


\section{http://dx.doi.org/10.21611/qirt.2004.079}

In figures 4 and 5 , the obtained results after investigating blank sample 1 with sample S1 are presented. The increased thermal energy that was deposited on the plastered surface with the extended heating time utilised, produced a seeing-through situation on the examined panels. The increased thermal contrast developed, also reveals this. The blank sample 1 cools down with relatively faster rate when compared to the plastered mosaic surface. This is mainly due to the presence of tesserae in sample S1, as well as to the presence of hydraulic lime, which has lower thermal conductivity than the lime mortar will loose its thermal energy at a slower rate.

Similarly, the next investigated pair of samples (Blank 1 with S2) is presented in figures 6 and 7. Once more, the thermal contrast curves show this. However, an increased temperature difference $(\Delta T)$ is presented, when compared to the previous investigated pair of panels (i.e. blank 1 and S1). This is possibly due to the different thermal properties (i.e. lower thermal conductivity of the marble tesserae) that the marble tesserae of sample S2 have in relation to the gold and enamel tesserae of sample S1. This is also due to the extensive heating time that was used in the experiments.

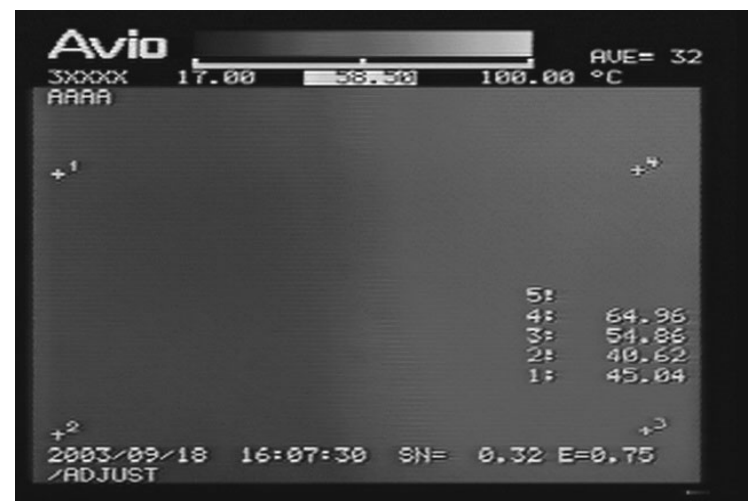

Fig. 6. Thermal image showing the blank sample 1 (left) and sample S2 (right) obtained at 30 minutes.

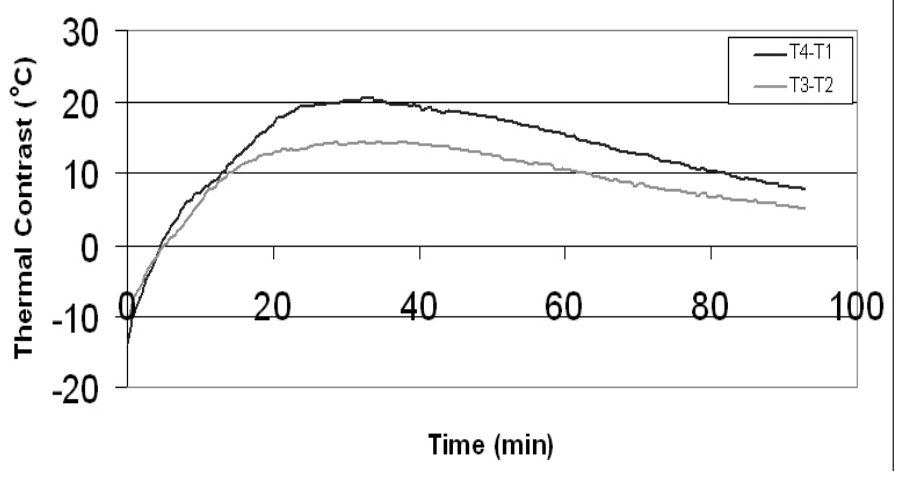

Fig. 7. Thermal contrast curves of blank sample 1and sample S2. 
By comparing the two pairs tested, the first pair where the gold and enamel tesserae are present shows a different behaviour in relation to the other tested pair where the tesserae are from marble. For instance, the thermal contrast curves in the first situation are much lower than in the marble case. This is due to the different thermal properties (i.e. lower thermal conductivity) that the marble has in comparison to the gold and enamel.

Another investigated pair of samples (Blank 1 and Blank 2) is presented in figures 8 and 9 . An increased temperature is presented in sample Blank 2, when compared to sample Blank 1 . This verifies the statement that the hydraulic lime mortar has a lower thermal conductivity when compared to the lime mortar, i.e. looses its temperature at a slower rate.

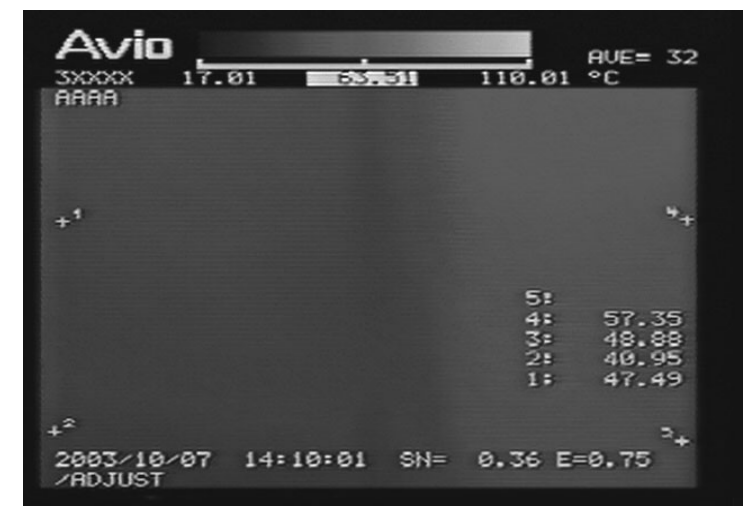

Fig. 8. Thermal image showing the blank sample 1 (left) and blank sample 2 (right) obtained at 25 minutes.

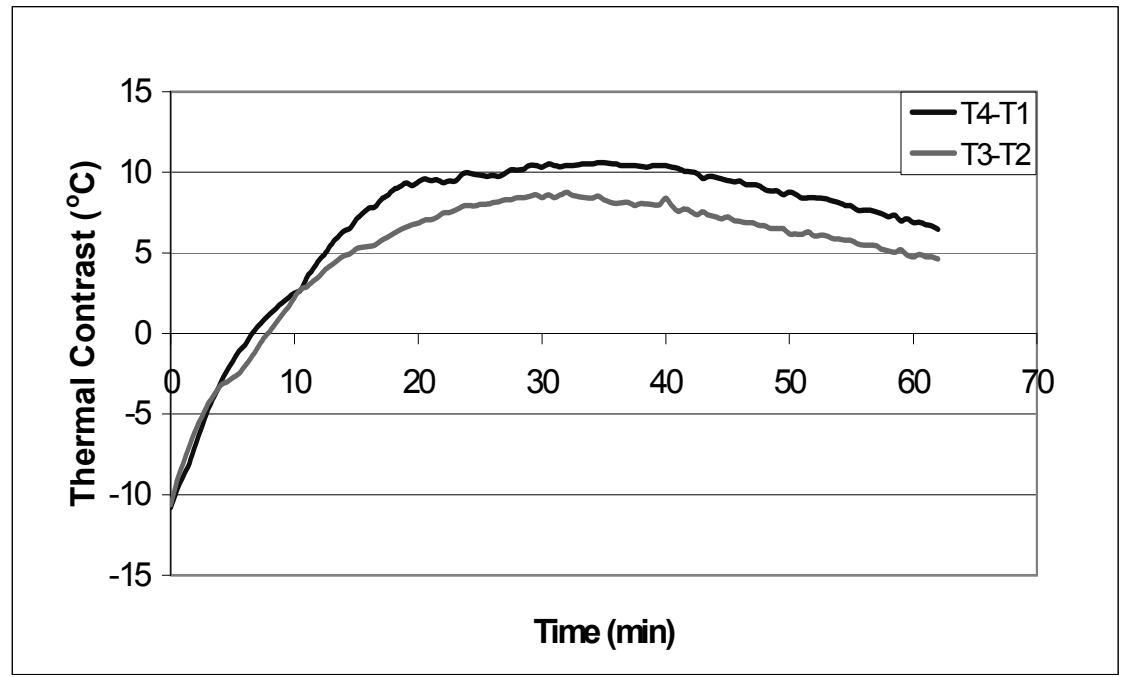

Fig. 9. Thermal contrast curves of blank sample 1and blank sample 2. 
From the other two investigated pairs of samples (i.e. blank 2 with S3 and blank 2 with S4) it was observed that the samples with the plastered mosaic (i.e. S3 and S4) presented lower temperature values in relation to the blank sample. Since the thermal conductivity is the same for all three samples due to the presence of the hydraulic lime mortar on the plastered surface, this temperature difference can be attributed to the presence of sub surfaces in samples S3 and S4 (i.e. tesserae from gold and enamel or marble).

\section{Conclusions}

This study has shown that images seeing through the mortar on plastered mosaic surfaces can be obtained using the principles of transient thermography. The technique was used effectively in the detection of subsurface layers (i.e. tesserae) under specific testing requirements. Conclusively, transient thermography ought to be considered as a valuable appraisal tool in the investigation of plastered mosaic surfaces.

\section{REFERENCES}

[1] Avdelidis, N.P. and Moropoulou, A. Review Paper: Applications of infrared thermography for the investigation of historic structures, Journal of Cultural Heritage, 5, 119-127, (2004).

[2] Avdelidis, N.P., Hawtin, B.C. and Almond, D.P. Transient thermography in the assessment of defects of aircraft composites, Journal of NDT \& E International, 36, 433-439, (2003).

[3] Maierhofer, Ch., Brink, A, Rollig, M. and Wiggenhauser, H. Detection of shallow voids in concrete structures with impulse thermography and radar, Journal of NDT \& E International, 36, 257-263, (2003).

[4] Moropoulou, A., Avdelidis, N.P., Koui, M. and Kakaras, K. An application of thermography for detection of delaminations in airport pavements, Journal of NDT \& E International, 34, 329-335, (2001).

[5] Avdelidis, N.P. and Almond, D.P. Through skin sensing assessment of aircraft structures using pulsed thermography, Journal of NDT \& E International, 37, 353-359, (2004).

[6] Moropoulou, A., Aggelakopoulou, E., Avdelidis, N.P. and Koui, M. Nondestructive techniques for the characterization of structural materials, The undergraduate Curriculum in Materials Science and Engineering, Eds: E.P. Douglas, O.D. Dubon Jr, J.A. Isaacs, W.B. Knowlton, M.S. Whittingham, Vol. 760E, Publ. Materials Research Society, Pittsburgh (2003), Electronic Publication.

[7] Moropoulou, A., Avdelidis, N.P., Aggelakopoulou, E., Griniezakis, S., Koui, M., Aggelopoulos, A., Karmis, P. and Uzunoglou, N.K. Examination of plastered mosaic surfaces using NDT techniques, Journal of Insight, 43, 241-243, (2001). 